\title{
CASA FANLO
}

Francisco Gutiérrez Morales

Miguel Angel de Pablo Ortega

Fernando Ródenas Moreno

Gemma San Vicente Aguirreurreta

Carlos Serrano Marcos

La Casa Fanlo se encuentra situada en la parte alta del pueblo, en la ladera del monte.

Es un edificio muy antiguo, sabiéndose que perteneció en el siglo XV al obispo de Jaca. Desde entonces hasta que fue abandonado ha ido sufriendo una serie de modificaciones que lo han ido adaptando a las nuevas necesidades de sus moradores.

La denominación de "Casa Fanlo» o "Casa de los Fanlos» se debe al apellido de los que alli vivían, pasando la casa de padres a hijos durante generaciones.
El edificio en sí consta de tres plantas, y falsa o almacén. La planta baja se utilizaba como patio, establo o cuadra, y bodega o almacén para guardar los productos del campo.

La entrada principal está formada por un arco de medio punto en piedra, y sobre la clave aparece tallado un curioso símbolo: "La Hexafolia pirenaica", que está constituida por seis hojas en estrella rodeadas de otras seis hojas formando hexágono. Desconocemos cuál es exactamente su significado pero sabemos que está relacionado con la fecundidad.

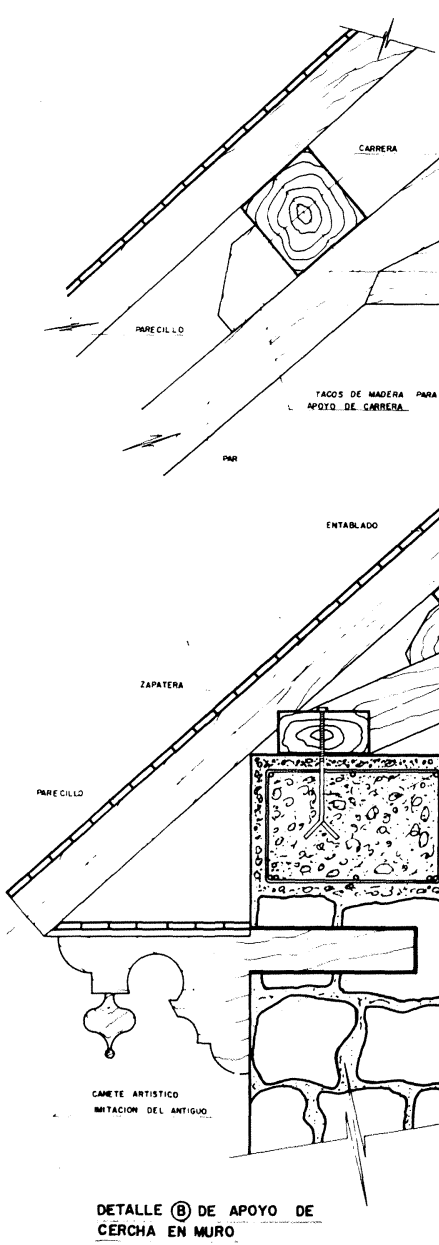


Construido con posterioridad al resto, la casa tiene un anexo que se une al edificio principal mediante una bóveda de cañón, y consta de una leñera abovedada en planta baja y de otras dos plantas; éstas a distinta altura que las del edificio principal, y comunicadas con aquéllas mediante sendos huecos realizados en los muros.

Las distintas plantas del edificio se comunican entre sí mediante una escalera realizada totalmente en madera y formada por zancas corridas que apoyan directamente sobre el forjado, constituyendo uno de los elementos más característicos de este edificio.

La planta primera consta de varias dependencias, entre las que cabe destacar un salón grande, el cual comunica con dos pequeños dormitorios, y cuyas paredes están decoradas con pinturas que tienen un carácter casi aristocrático. En esta misma planta hay también otros dormitorios, una pequeña cocina y una salida al exterior del edificio por su parte trasera.

En el anexo se encontraba la cocina principal, en donde se hacía la vida diurna, ya que en ella se encuentra la chimenea u horno, hecho con piedra tosca y que servía para cocinar además de como calefacción.

En la planta segunda se encuentran el resto de los dormitorios, habiendo un aseo en voladizo que sobresale de la fachada posterior, y que fue añadido al edificio en un momento determinado, estando hoy totalmente derruido. La planta segunda comunica con la falsa mediante una escalera de madera de un sólo tramo.

La última planta, o falsa, se utilizaba como almacén de grano y paja, actuando además como aislante térmico, y quedando abuhardillada por la cubierta, la cual está formada por cerchas de madera apoyadas en los muros exteriores de carga mediante la interposición de una viga de madera (zapatera) colocada sobre el muro para repartir la carga que transmiten los pares de las cerchas. Cada cercha está constituida básicamente por dos pares y dos tirantes, uno de ellos situado a una altura intermedia de la cercha.

La pendiente de la cubierta es de unos $45^{\circ}$, y está formada por pizarras clavadas sobre entablillado de madera. Estas pizarras tienen un color rojizo característico debido a su alto contenido en hierro.

Todos los muros de carga del edificio están realizados en piedra tomada con mortero bastardo de cal, y su espesor oscila entre los 50 y $70 \mathrm{~cm}$.

Los huecos realizados en los muros están resueltos mediante dinteles de piedra o de madera.

Los muros no tienen cimentación pues apoyan directamente en el terreno, que es de roca.

La estructura horizontal está resuelta mediante forjado de viguetas de madera sobre las cuales apoyan las tablas que forman el suelo. En algunos sitios el espacio entre viguetas se rellena además con cañas unidas con yeso, y sobre ellas van el entablado de madera, de un espesor entre 3 y $4 \mathrm{~cm}$.

Las vigas de madera apoyan directamente sobre los muros o bien sobre otras vigas que descansan sobre unas pequeñas ménsulas de piedra empotradas en el muro.

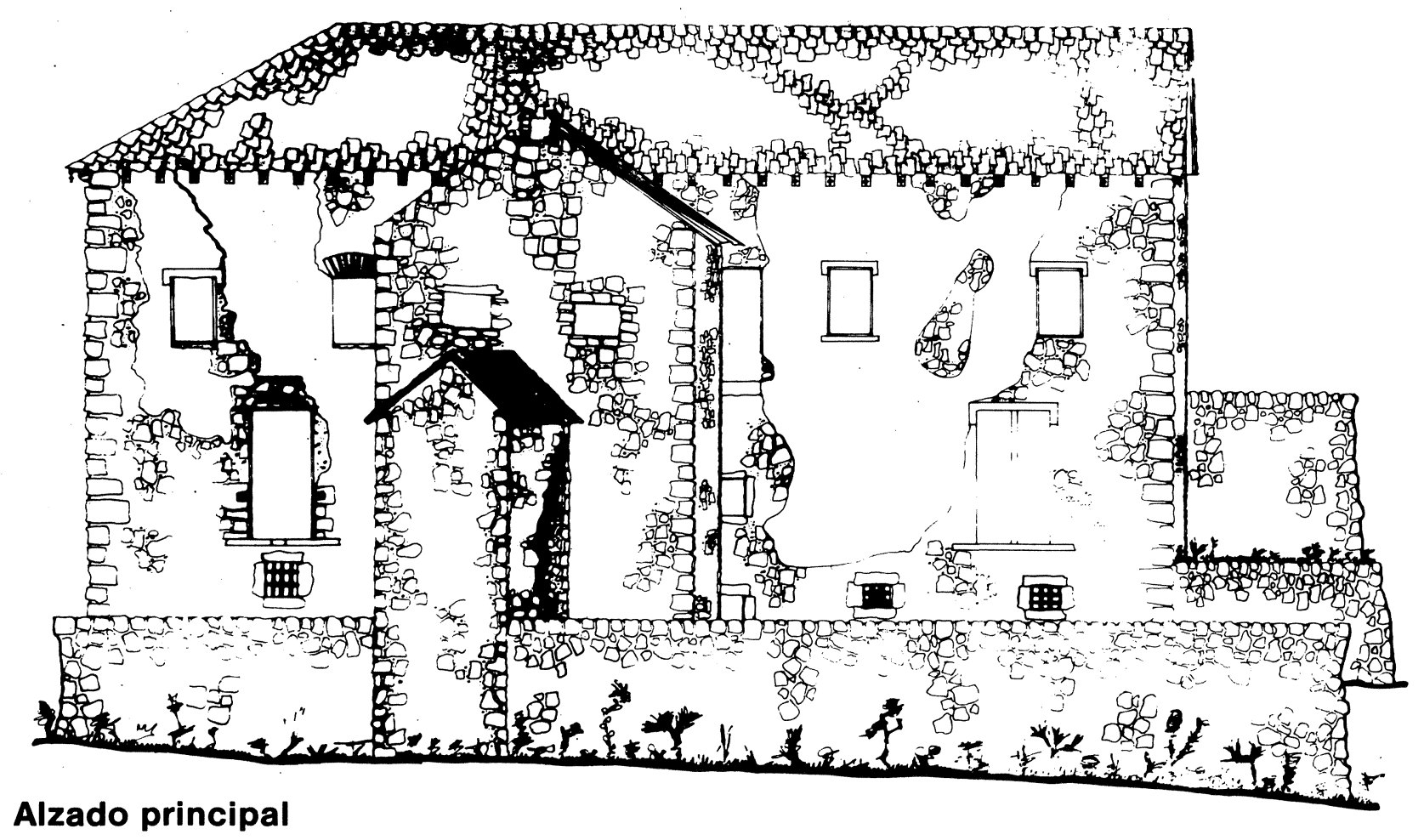




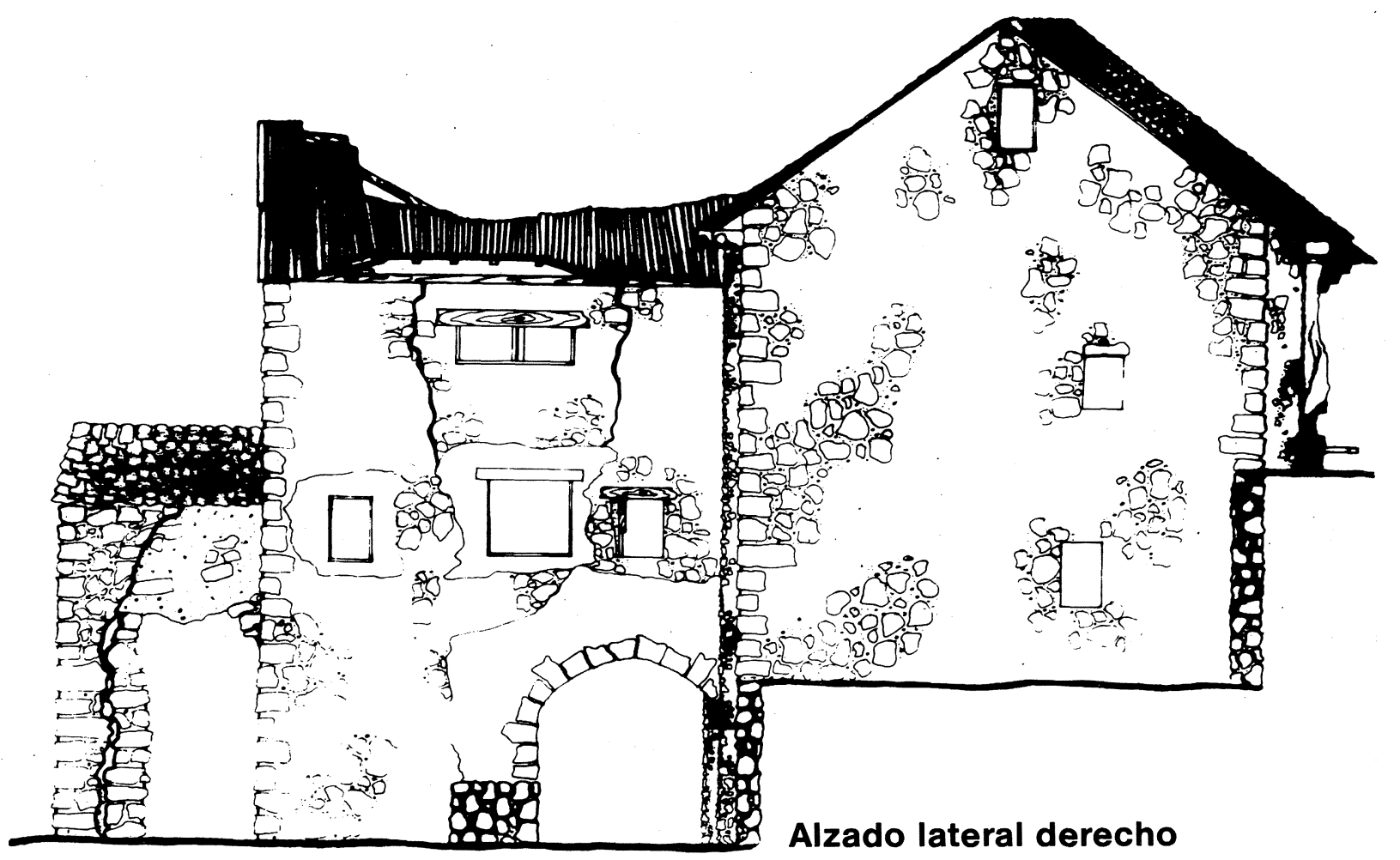

Las alturas entre pisos oscilan alrededor de los dos metros y medio.

Por estar el edificio en una zona en que el terreno está en pendiente, parte de la planta baja queda "enterrada» y la propia roca hace de muro de cerramiento y carga.

La tabiquería está resuelta, en los tabiques más antiguos, mediante telares compuestos por piedra, mortero y tomiza, que cubren los huecos que quedan entre los elementos verticales de madera que forman el esqueleto del tabique.

Los tabiques más recientes están formados por pequeñas tablillas de madera horizontales, clavadas a otras verticales y cubiertas después con yeso.

Otro de los elementos característicos de este edificio son los canetes de madera que forman el alero de la cubierta, y que son verdaderas piezas de artesania de gran belleza.

\section{Estado patológico del edificio}

Desde el abandono del pueblo, los edificios de Búbal se han ido deteriorando debido al expolio cometido por los vecinos de otros pueblos y debido a las inclemencias del tiempo.

Concretamente en "nuestro" edificio han robado una inscripción en piedra que había en la fachada; han sido

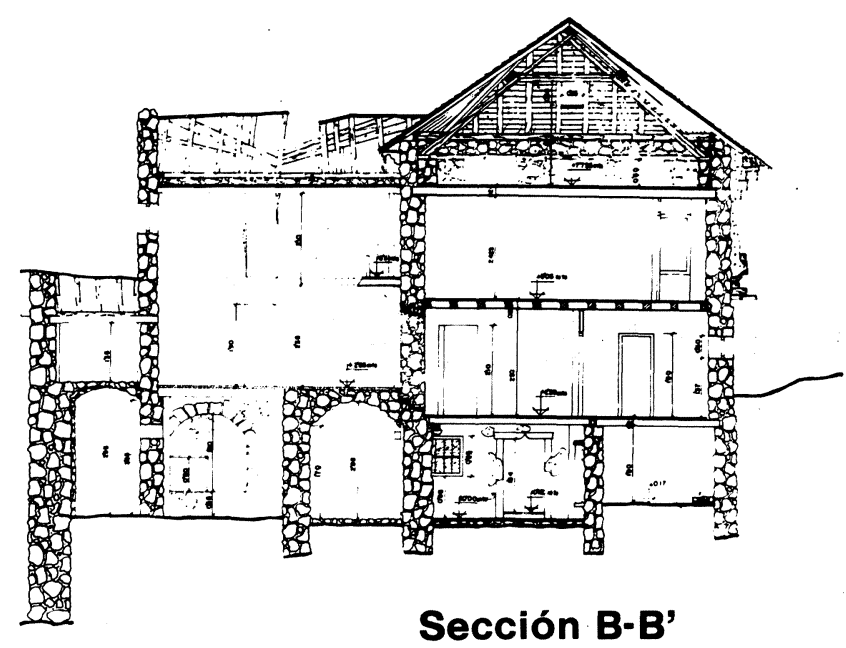

arrancadas las tablas de madera de los suelos, dejando al descubierto casi todos los forjados; se han llevado puertas, ventanas, barandillas de balcones y escaleras; todo esto, sumado a la acción de la nieve, la humedad, la lluvia, etc., ha provocado el que se pudran los forjados y que se vengan abajo las cubiertas dejando al edificio en un estado bastante deplorable.

También se han producido asentamientos que han llevado consigo la aparición de grietas en los muros.

El horno se encuentra en un pequeño anexo situado en la parte delantera de la casa, y descansa sobre una pequeña bóveda. El conjunto queda coronado por una cubierta a dos aguas. 


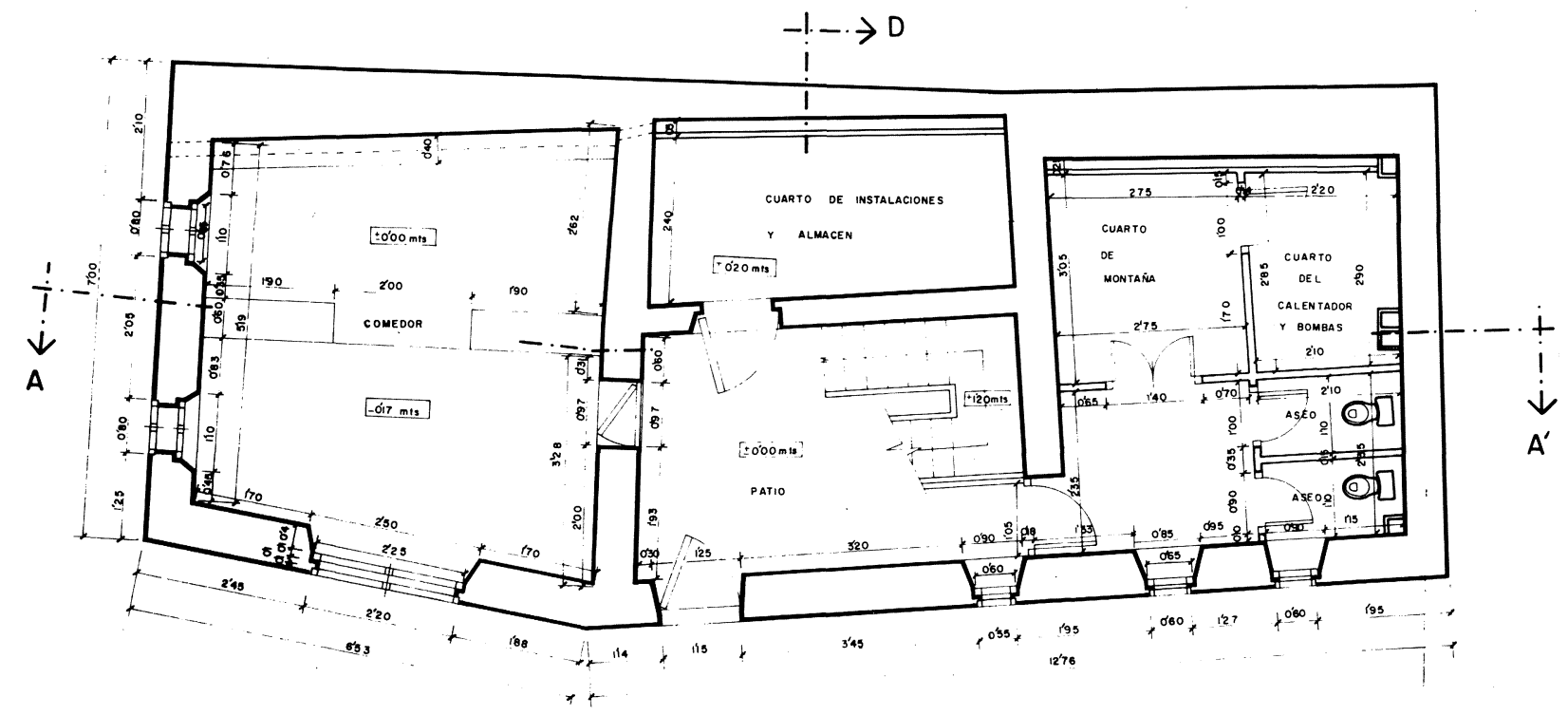

Distribución planta baja

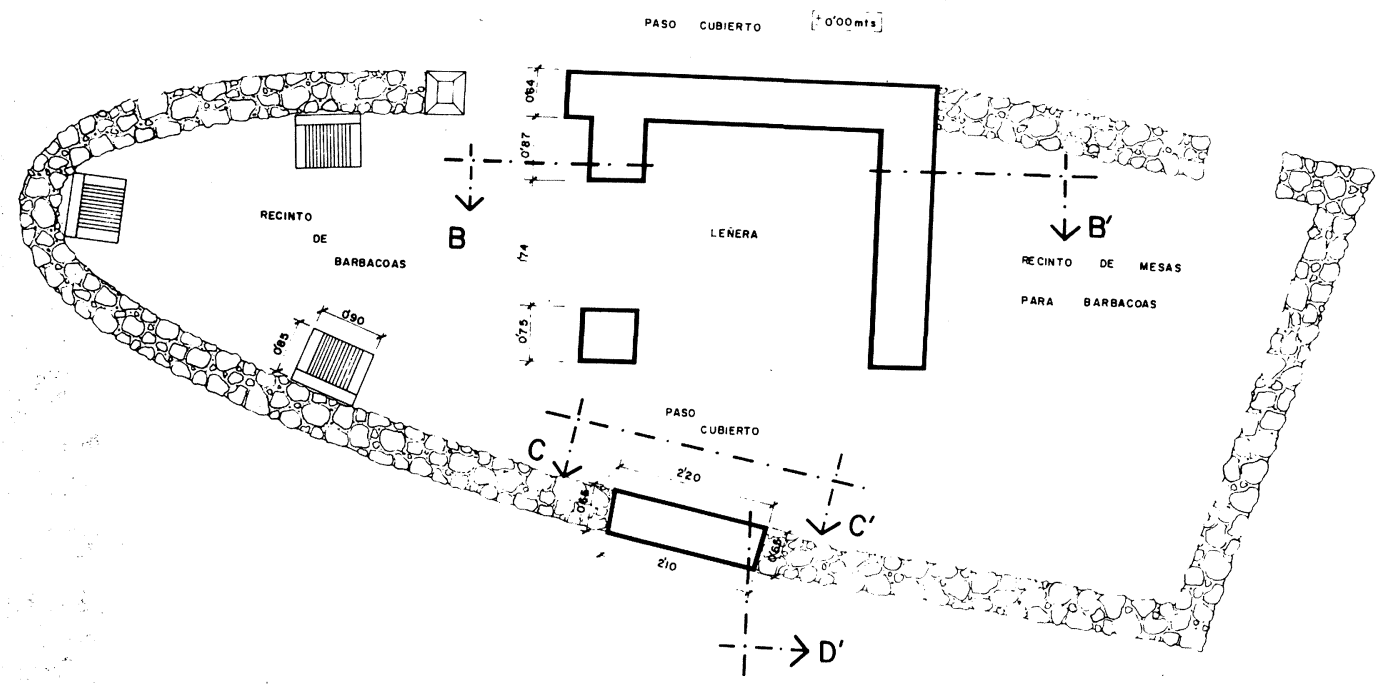

Tanto el horno como la bóveda están casi totalmente destruidos.

El tiro del horno o chimenea discurre por el interior del muro del segundo anexo, el cual tiene totalmente derruida la cubierta y podridos los forjados de madera, siendo la parte del edificio que se encuentra en peor estado.

En cuanto a la cubierta del edificio principal, ésta tiene numerosos agujeros por los que entra el agua, provocando la destrucción de la madera.

\section{NUEVO DESTINO DEL EDIFICIO}

El edificio se pretende destinar a albergue de montaña.

El estudio consistia, por tanto, en adaptar el edificio antiguo a las necesidades requeridas por su futura fun- ción, creando una nueva distribución y dotándole de las instalaciones y servicios necesarios para este fin. Todo esto manteniendo en lo posible su anterior fisonomía y conservando todo aquello que lo caracterizase como construcción típica de esta zona del Pirineo, y que en definitiva representará un modo de vida y unas costumbres que constituyen la cultura de un pueblo.

En planta baja, y en la zona que suponemos era un corral delimitado por un muro de piedra, se habilitará un recinto para barbacoas al aire libre. La antigua leñera se mantiene y se utilizará como tal.

La planta baja del edificio principal constará de: un patio distribuidor donde se encuentra la escalera, un comedor, un cuarto de instalaciones y almacén, y una zona de aseos. En esta planta prácticamente se ha mantenido la antigua distribución, convirtiendo la bodega en comedor y el establo en zona de servicios, y conservando la esca- 
lera en el lugar que estaba, así como el patio y el almacén. En el comedor se han tenido que abrir algunos huecos, pues la antigua bodega carecia prácticamente de luz.

La planta primera constará de una zona de distribución o hall al que da la escalera, un comedor, una cocina y un cuarto de estar-comedor que comunica con el horno, el cual tendrá una función meramente representativa.

El comedor es el antiguo salón; la cocina era antes zona de dormitorios, y el estar-comedor era la antigua cocina de la casa. En esta planta se han mantenido también todos los muros y huecos exteriores que antes existian.

Al llegar a la planta segunda la escalera se bifurca en dos tramos opuestos que nos sirven para dividir la planta en dos zonas, ambas compuestas por un dormitorio comunal y una zona de servicios y duchas.

En esta misma planta y en el anexo se habilitará un salón mirador con chimenea y con una balconada en voladizo que no existía antes pero que es frecuente encontrarnos en los pueblos del alto pirineo aragonés.

Por otra parte ésta es la zona del edificio que se encuentra en peor estado y hay que rehacerla entera de todas las maneras.

En cuanto al servicio en voladizo que existia, lo hemos sustituido por un balcón en uno de los dormitorios, ya que además de estar totalmente destruido no tenía razón de ser en el nuevo destino del edificio.

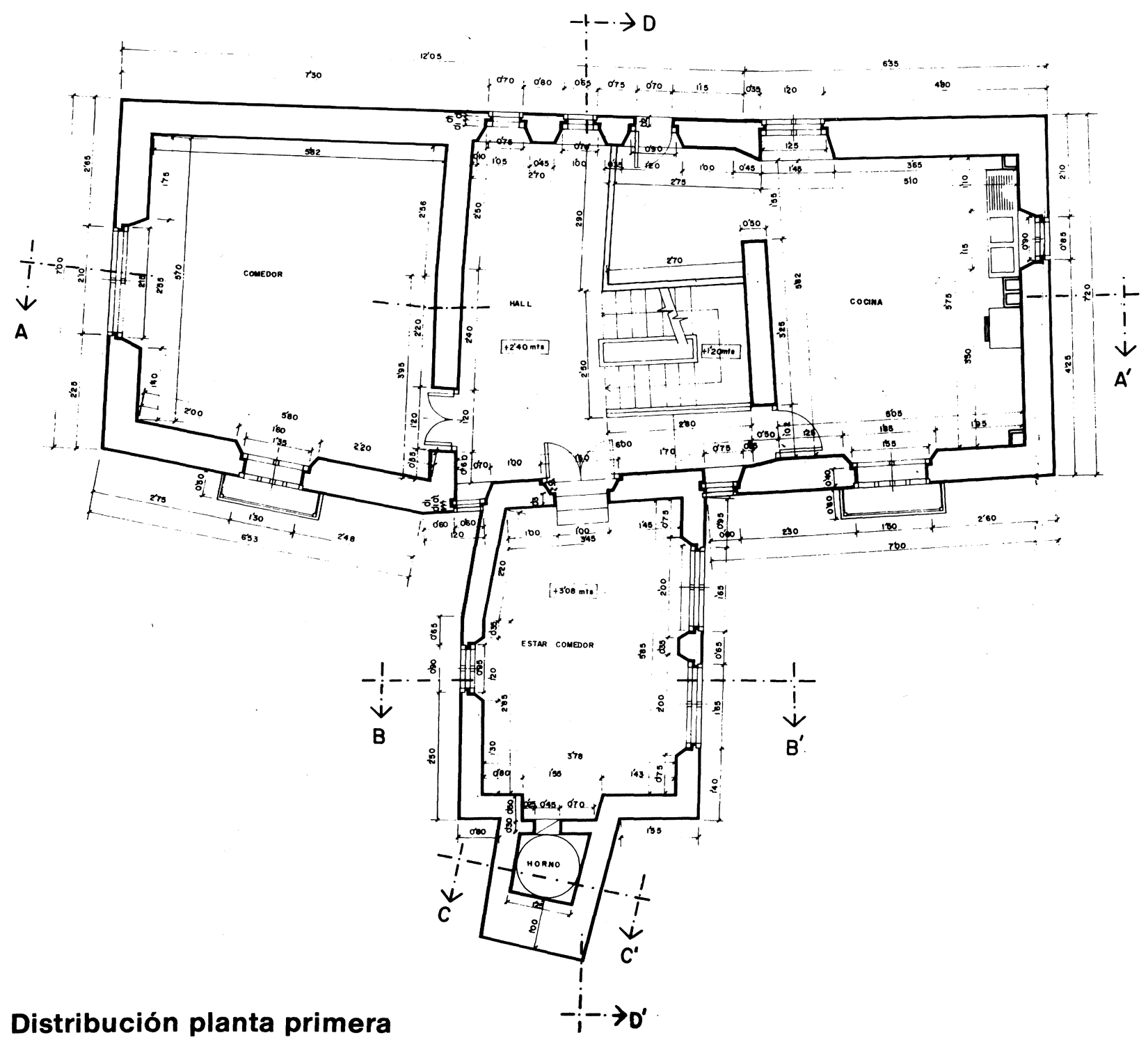


La planta tercera es la antigua falsa o almacén, y su nuevo destino es el de dormitorios con dos cuartos independientes de servicios y duchas. La antigua disposición de las cerchas no nos servia para habilitar esta planta debido a que entorpecian el paso, y hemos tenido que ir a otra solución de cercha que nos permitiera ganar altura.

Por otra parte, y por la misma razón de la falta de espacio apuntada, se ha elevado la altura de los muros en medio metro.

Los canetes que forman el alero de la cubierta se recuperarán y se colocarán tal y como estaban antes, y si no fuera posible recuperarlos todos, se sustituirán los restantes por otros nuevos, reproducción de los antiguos.

La luz y ventilación de la planta de cubierta se ha realizado mediante mansardas, también llamadas locanas.

\section{MODIFICACIONES EN LA ESTRUCTURA}

Los muros de carga del edificio principal se mantendrán como estaban previo picado y rejuntado, y se arriostrarán mediante dos zunchos perimetrales de hormigón, uno en planta baja y otro en planta de cubierta.

En el anexo habrá que sustituir parte de los muros por encontrarse éstos en peor estado.

Las bóvedas se mantendrán como están reparándolas, pero no tendrán función resistente, ya que las cargas las recibirá ahora un nuevo forjado cuyas viguetas apoyarán en los muros, a excepción de la bóveda que sostiene al horno, la cual será totalmente reconstruida y servirá de apoyo al horno y a su cubierta.

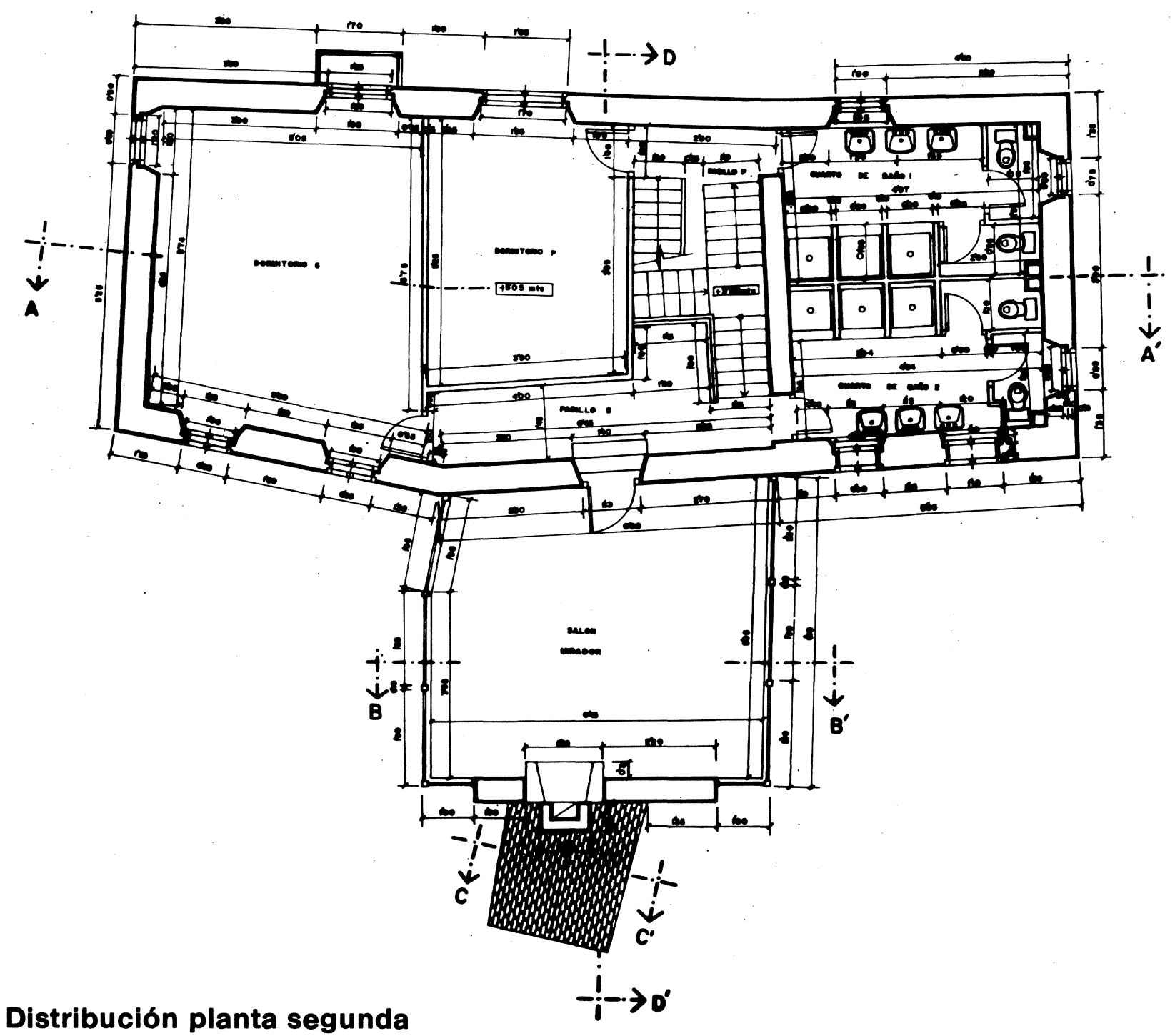




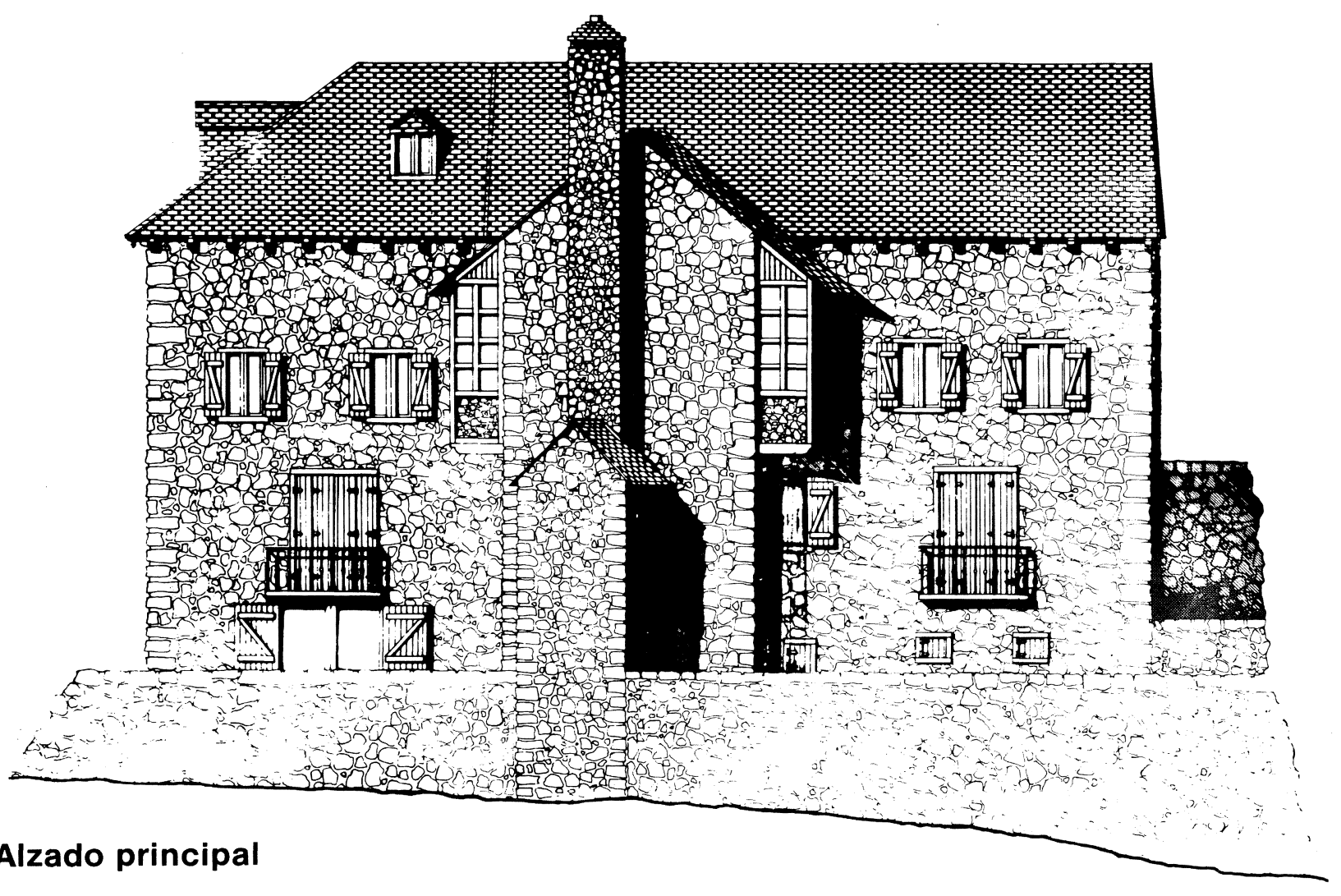

\section{Alzado principal}

Los forjados de las zonas comunes de distribución estarán compuestos, al igual que los que existian antes, por viguetas de madera de pino del país con entablado de madera de $4 \mathrm{~cm}$ de espesor, de modo que las viguetas queden vistas.

El resto de los forjados, que irán ocultos, estarán formados por viguetas autorresistentes de hormigón, que apoyarán directamente sobre los muros de piedra, y sobre vigas planas de hormigón armado en aquellos casos en los que la luz de las viguetas así lo ha requerido.

De la antigua chimenea no quedaba prácticamente nada, asi que para hacernos una idea de cómo la teniamos que resolver nos tuvimos que basar en las chimeneas existentes en los pueblos de la zona, las cuales están realizadas en piedra tosca, y elegimos una coronación a base de placas de piedra en capas superpuestas.

En cuanto a la estructura del edificio no hay mucho más que decir, ya que lo fundamental, que son los gruesos muros de piedra, se han mantenido como estaban.

El estado final del edificio, suponiendo que se realice como nosotros hemos pensado, es el que muestra el plano.

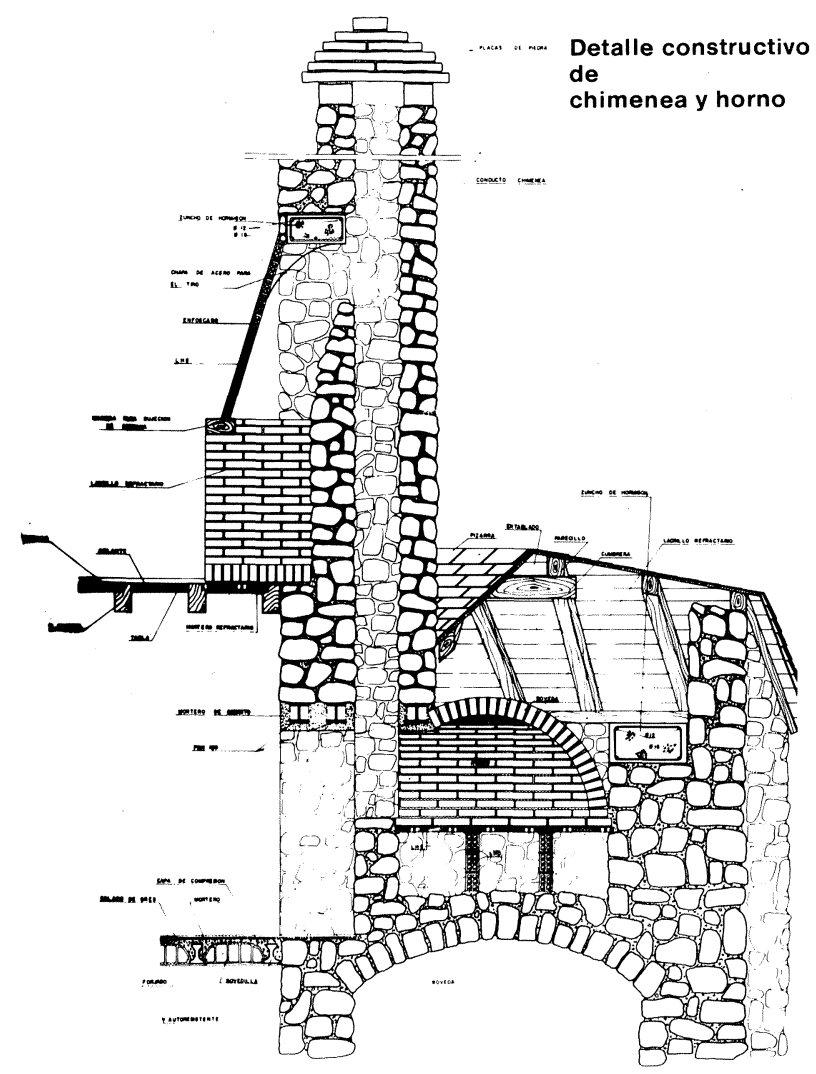

